
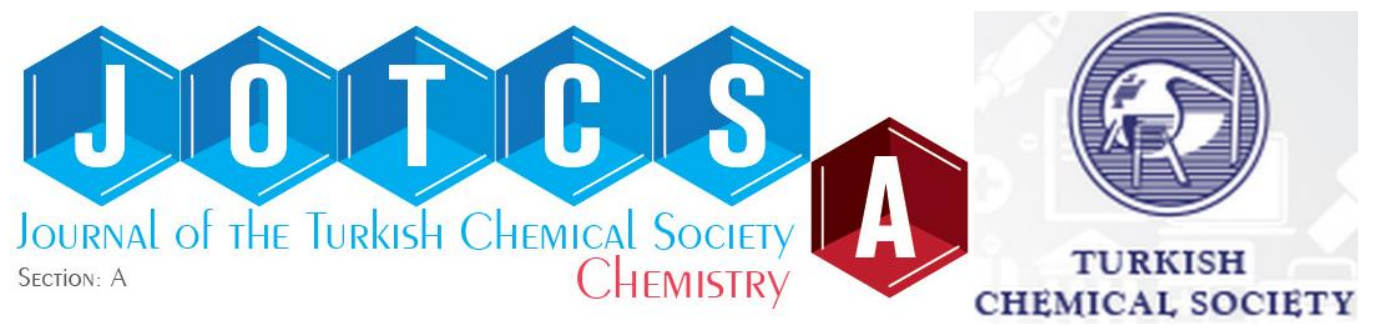

\title{
Ferulic Acid Substituted Zn(II) Phthalocyanine: Synthesis, Characterization and Investigation of Photophysical and Photochemical Properties
}

\author{
Semih Gorduk $\triangle$ D* \\ Yildiz Technical University, Faculty of Arts and Science, Department of Chemistry, 34210, Istanbul, Turkey.
}

Abstract: In this study, novel peripherally ferulic acid tetra-substituted $\mathrm{Zn}$ (II) phthalocyanine was synthesized for the first time. The synthesized phthalocyanine was characterized by elemental analysis, infrared spectroscopy, UV-Vis spectrophotometry, ${ }^{1} \mathrm{H}$-NMR spectroscopy, and MALDI-TOF MS techniques. The photophysical, photochemical and aggregation properties of this phthalocyanine were also investigated in DMSO and DMF solvents. The aggregation studies showed that the synthesized $\mathrm{Zn}$ (II) phthalocyanine does not aggregate in DMSO and DMF. Fluorescence quantum yield ( $\Phi_{F}: 0.23$ in DMSO and 0.17 in DMF), singlet oxygen quantum yield ( $\Phi_{\Delta}: 0.57$ in DMSO and 0.45 in DMF) and photodegradation quantum yield $\left(\Phi_{\mathrm{d}}: 1.08 \times 10^{-5}\right.$ in DMSO and $4.44 \times 10^{-5}$ in DMF) were also determined. These results show that the synthesized phthalocyanine has potential use in photodynamic therapy.

Keywords: Ferulic acid, Phthalocyanine, Photochemical, Photophysical, Zinc

Submitted: June 28, 2018. Accepted: July 18, 2018.

Cite this: Gördük S. Ferulic Acid Substituted Zn(II) Phthalocyanine: Synthesis, Characterization and Investigation of Photophysical and Photochemical Properties. JOTCSA. 2018;5(2):903-18.

DOI: http://dx.doi.org/10.18596/jotcsa.438111.

*Corresponding author. E-mail: semih_grdk@hotmail.com, sgorduk@yildiz.edu.tr, Tel: +90212 383 4129.

\section{INTRODUCTION}

In the recent years, phthalocyanines (Pcs) have been comprehensively studied by scientists due to their unique chemical, physical, optical and structural properties such as aromatic $18-\pi$ conjugated electron systems, very versatile and stabile aromatic macrocyclic ring, strong and long-wavelength absorption, high thermal stability, chemical resistance, photoconductivity, and catalytic activity (1-3). Because of these properties, Pcs have been used in many applications. For example, catalysis (4), liquid crystals (5), chemical sensors (6), semiconductor materials (7), photovoltaics (8), electrochemistry $(9,10)$, photodynamic therapy (PDT) (11) are important areas in which Pcs are used. In particular, metallo Pcs can absorb at high wavelength lights near the red region of light. With this feature, they are used in photodynamic therapy as photosensitizers suitable for cancer treatment studies (12).
Photodynamic therapy (PDT) is a process in which compounds called as photosensitizers absorb light in a specific wavelength, lower energy triplet into a high energy singlet and thus causing the destruction of the cancerous cells in the area where the photosensitizers are located (13). Pcs exhibit photosensitizer properties (14). Pcs containing diamagnetic metal ions ( $\mathrm{Zn}, \mathrm{Ga}, \mathrm{In}, \mathrm{Si})$ are photoactive and are usually utilized in PDT due to their high efficiency of cytotoxic singlet oxygen photogeneration and long triplet lifetimes $(15,16)$. However, Pcs have disadvantage such as insolubility in common organic solvents. The use of Pcs is limited due to this disadvantage. Alkyl, alkoxy/alkylthio, sulfonyl, carboxyl and quaternized ammonium groups may be used in peripheral and non-peripheral positions to overcome this disadvantage (17-19). Especially, carboxylic acid groups are particularly useful to acquire solubility in common organic solvents and water (20-22). There are many studies in the literature that include carboxylic acid groups to increase solubility and prevent aggregation (23). 
For example, ZnPc bearing 16-carboxylic acid groups was reported by M. Liu et al. (2005) to diminish aggregation for utilize as a potential photosensitizer for PDT (24). M.-R. Ke et al. (2009) synthesized non-peripherally and peripherally tetra-substituted with carboxylic acid zinc(II) Pcs as photosensitizers (25). Beta and alpha tetra-[4-oxy-3-methoxybenzoic acid]substituted $\mathrm{Zn}(\mathrm{II}), \mathrm{Co}(\mathrm{II})$ and $\mathrm{Cu}(\mathrm{II})$ Pcs were reported by G. Özgül et al. (2015) for comparative electrochemistry studies (26).

Herein, we reported synthesis and characterization of ferulic acid functionalized peripherally tetra-substituted Zn(II) phthalocyanine. Zinc(II) Pcs have a high singlet oxygen quantum yield and thus they were studied as photosensitizers for PDT. For this reason, we investigated the aggregation, photophysical and photochemical properties of the $\mathrm{Zn}$ (II) phthalocyanine synthesized here. Fluorescence quantum yield, singlet oxygen quantum yield and photodegradation quantum yield indicate that this compound is a potential photosensitizer in the PDT.

\section{MATERIALS AND METHODS}

\section{Chemical and Reagents}

Trans-ferulic acid (trans-4-hydroxy-3methoxycinnamic acid), 4-nitrophthalonitrile, zinc(II) acetate, 1,3-diphenylisobenzofuran (DPBF), potassium carbonate $\left(\mathrm{K}_{2} \mathrm{CO}_{3}\right)$, and $1,8-$ diazabicyclo[5.4.0]undec-7-ene (DBU) were purchased from Sigma-Aldrich and TCI chemical companies. All chemicals and solvents were acquired with high purity from commercial suppliers. All solvents were dried and stored over molecular sieves.

\section{Equipments}

Melting points of the substances were determined using an Electrothermal Gallenkamp device. The IR spectra were recorded using a Perkin Elmer spectrometer with ATR sampling accessory. The UV-Vis spectra were recorded on an Agilent 8453 UV/Vis spectrophotometer. Elemental analysis was carried out by a LECO CHNS 932 instrument. A Varian Unity Inova $500 \mathrm{MHz}$ spectrometer was used for ${ }^{1} \mathrm{H}-\mathrm{NMR}$ and ${ }^{13} \mathrm{C}-\mathrm{NMR}$ spectra. MALDITOF mass spectrum was performed using a Bruker Microflex LT MALDI-TOF-MS. The LC-MS spectrum was obtained on a Shimadzu LCMS8030 Plus. Fluorescence spectra were measured using a Varian Eclipse spectrofluorometer using 1 $\mathrm{cm}$ path length cuvettes at room temperature. In photochemical measurements, UV-Vis spectra were recorded on a Shimadzu UV-2001 UV-Vis spectrophotometer.

Photoirradiation studies were performed using a General Electric quartz line lamp (300 W). A 600 $\mathrm{nm}$ glass cut off filter (Schott) and a water filter were used to filter off ultraviolet and infrared radiations, respectively. An interference filter (Intor, $670 \mathrm{~nm}$ with a band width of $40 \mathrm{~nm}$ ) was additionally placed in the light path before the sample. Light intensities were measured with a POWER MAX5100 (Molelectron detector incorporated) power meter.

\section{Photophysical and Photochemical Parameters}

Fluorescence quantum yield determination

Fluorescence quantum yields $\left(\Phi_{\mathrm{F}}\right)$ were calculated by the comparative method (Eq. 1) $(27,28)$ using unsubstituted $\mathrm{Zn}$ (II) phthalocyanine as the reference. $\Phi_{\mathrm{F}}$ values of unsubstituted $\mathrm{Zn}$ (II) phthalocyanine are 0.20 in DMSO and is 0.17 in DMF $(29,30)$.

$$
\Phi_{\mathrm{F}}=\Phi_{\mathrm{F}}(\mathrm{Std}) \frac{\mathrm{F} \cdot \mathrm{Astd} \cdot \mathrm{n}^{2}}{\mathrm{Fstd}_{\mathrm{Std}} \mathrm{A} \cdot \mathrm{n}_{\mathrm{Std}}^{2}}
$$

Where $F$ and $F_{\text {Std }}$ are the areas under the fluorescence emission curves of the sample (The synthesized phthalocyanine) and the standard, respectively. A and $A_{s t d}$ are the respective absorbances of the sample and standard at the excitation wavelengths. $n$ and $n_{\text {std }}$ are the refractive indices of solvents used for the samples and standard, respectively.

\section{Singlet oxygen quantum yield determination}

Singlet oxygen quantum yield $\left(\Phi_{\Delta}\right)$ determinations were carried out using the experimental setup described in the literature
$(22,30,31)$ with standard unsubstituted $\mathrm{Zn}$ (II) phthalocyanine (in DMSO and DMF) as the reference. Typically, a $2 \mathrm{~mL}$ portion of the zinc(II) phthalocyanine solution $\left(C=1.0 \times 10^{-5} \mathrm{M}\right)$ that contained the singlet oxygen scavenger was irradiated in the Q-band region with the photoirradiation setup described in the literature. The $\Phi_{\Delta}$ values were determined in air using the relative method with DPBF as a singlet oxygen chemical scavenger in DMSO and DMF using Eq. 2 .

$$
\Phi_{\Delta}=\Phi_{\Delta}^{\mathrm{Std}} \frac{\mathrm{R} \cdot \mathrm{I}_{\mathrm{abs}}^{\mathrm{Std}}}{\mathrm{R}^{\mathrm{Std}} \cdot \mathrm{I}_{\mathrm{abs}}}
$$


$\Phi_{\Delta}^{\text {Std }}$ is the singlet oxygen quantum yield for the standard unsubstituted $\mathrm{Zn}$ (II) phthalocyanine ( $\Phi_{\Delta}^{\text {Std }}$

${ }_{\Delta}=0.67$ in DMSO and 0.56 in DMF) (32) (27). $\mathrm{R}$ and $\mathrm{R}_{\mathrm{Std}}$ are the DPBF photobleaching rates in the presence of the respective sample zinc(II) phthalocyanine and standard $\mathrm{Zn}$ (II) phthalocyanine, respectively. $\mathrm{I}_{\mathrm{abs}}$ and $\mathrm{I}_{\mathrm{abs}}^{\mathrm{std}}$ are the rates of light absorption by the sample zinc(II) phthalocyanine and standard unsubstituted zinc(II) phthalocyanine, respectively. To avoid chain reactions induced by DPBF in the presence of singlet oxygen (33), the concentration of quenchers (DPBF) was lowered to $\sim 3 \times 10^{-5} \mathrm{M}$.
Solutions of the photosensitizer containing DPBF were prepared in the dark and irradiated in the Qband region using the setup described in equipment part. DPBF degradation at $417 \mathrm{~nm}$ was monitored. The light intensity of $2.20 \times 10^{16}$ photons. $\mathrm{s}^{-1} . \mathrm{cm}^{-2}$ was used for $\Phi_{\Delta}$ determinations.

Photodegradation quantum yield determination Photodegradation quantum yield $\left(\Phi_{\mathrm{d}}\right)$ determinations were carried out using the experimental set-up described in the literature (34-36). Photodegradation quantum yields of the sample (The synthesized phthalocyanine) were determined using Eq. 3.

$$
\Phi_{\mathrm{d}}=\frac{\left(\mathrm{C}_{0}-\mathrm{C}_{\mathrm{t}}\right) \cdot \mathrm{V} \cdot \mathrm{N}_{\mathrm{A}}}{\text { Iabs }_{\mathrm{S}} \mathrm{S} \cdot \mathrm{t}}
$$

Where $C_{o}$ and $C_{t}$ are the sample concentration before and after irradiation respectively. $V$ is the reaction volume. $N_{A}$ is the Avogadro's constant. $S$ is the irradiated cell area. $t$ is the irradiation time and $I_{a b s}$ is the overlap integral of the radiation source light intensity and the absorption of the sample. A light intensity of $7.05 \times 10^{15}$ photons. ${ }^{-}$ ${ }^{1} . \mathrm{cm}^{-2}$ was employed for $\Phi_{d}$ determinations.

\section{Synthesis of Compounds}

Synthesis of (E)-3-(4-(3,4-dicyanophenoxy)-3methoxyphenyl)acrylic acid (compound 1): Firstly, trans-4-hydroxy-3-methoxycinnamic acid (ferulic acid) (2.89 mmol, $0.56 \mathrm{~g}$ ) was dissolved in dry DMF $(50 \mathrm{~mL})$ and then 4-nitrophthalonitrile $(2.89 \mathrm{mmol}, 0.5 \mathrm{~g})$ was added into the solution. The solution was mixed for $15 \mathrm{~min}$ to obtain a homogenous mixture. Then, anhydrous $\mathrm{K}_{2} \mathrm{CO}_{3}$ $(11.56 \mathrm{mmol}, 1.59 \mathrm{~g})$ was added into the solution during 2 hours. The system was heated during 72 hours under nitrogen atmosphere at $45-50{ }^{\circ} \mathrm{C}$. The system was cooled to the room temperature at the end of the reaction and diluted $\mathrm{HCl}$ was added to set the $\mathrm{pH}$ to 2 . The solid particles were obtained in one hour. The particles were filtered and then washed with water, n-hexane, and diethyl ether. After drying process, light brown particles were recrystallized in $\mathrm{MeOH}$. The final product was soluble in many solvents such as $\mathrm{MeOH}$, EtOH, acetone, chloroform, and THF. Yield: $0.832 \mathrm{~g}$ (90.1\%), M.p.: 225-226 ${ }^{\circ} \mathrm{C}$, Anal. Calc. for $\mathrm{C}_{18} \mathrm{H}_{12} \mathrm{~N}_{2} \mathrm{O}_{4}$ (MA: $320.30 \mathrm{~g} / \mathrm{mol}$ ): C, $67.50 ; \mathrm{H}, 3.78 ; \mathrm{N}, 8.75$. Found: $\mathrm{C}, 67.30 ; \mathrm{H}$, $3.70 ; \mathrm{N}, 8.65 \%$. FT-IR $(\mathrm{KBr}), v_{\max } /\left(\mathrm{cm}^{-1}\right)$ : 3073$3047(\mathrm{Ar}-\mathrm{CH}), 3300-2500$ (broad peak, carboxylic acid-COOH), 2981-2844 (aliphatic $\left.-\mathrm{CH},-\mathrm{CH}_{3}\right), 2231(-\mathrm{C} \equiv \mathrm{N}), 1688(\mathrm{C}=\mathrm{O}), 1589-$ $1487(\mathrm{C}=\mathrm{C}), 1246$ ( $\mathrm{Ar}-\mathrm{O}-\mathrm{Ar}) .{ }^{1} \mathrm{H}-\mathrm{NMR}\left(\mathrm{MeOD}_{3}\right.$, $500 \mathrm{MHz}, \delta: \mathrm{ppm}): 12.45(\mathrm{~s}, 1 \mathrm{H},-\mathrm{OH}), 7.85-7.83$ (d, $1 \mathrm{H}, \mathrm{Ar}-\mathrm{H}), 7.69-7.65(\mathrm{~d}, 1 \mathrm{H}, \mathrm{Ar}-\mathrm{H}), 7.41-7.39$ (dd, $1 \mathrm{H} \mathrm{Ar}-\mathrm{H}$ ), 7.29 ( $\mathrm{s}, 1 \mathrm{H} \mathrm{Ar}-\mathrm{CH}=\mathrm{C}), 7.27$ (d, $1 \mathrm{H}, \mathrm{Ar}-\mathrm{H}), 7.21(\mathrm{~d}, 1 \mathrm{H}, \mathrm{Ar}-\mathrm{H}), 7.19-7.18(\mathrm{~d}, 1 \mathrm{H}$, $\mathrm{Ar}-\mathrm{H}), 6.53-6.50(\mathrm{~d}, 1 \mathrm{H},=\mathrm{CH}-\mathrm{COO}), 3.78(\mathrm{~s}, 3 \mathrm{H}$, $\left.\mathrm{O}-\mathrm{CH}_{3}\right) .{ }^{13} \mathrm{C}-\mathrm{NMR}\left(\mathrm{MeOD}_{3}, 500 \mathrm{MHz}, \delta: \mathrm{ppm}\right)$ : $170.23(-\mathrm{COOH}), 163.09,153.27,145.24$, 144.50 (Ar-C=C)，137.00，135.57，124.15，
$123.14,122.12,121.75,120.47,118.56$ (=C$\mathrm{COOH}), 116.65(-\mathrm{C} \equiv \mathrm{N}), 116.39(-\mathrm{C} \equiv \mathrm{N}), 113.78$, 109.76, $56.56\left(\mathrm{O}-\mathrm{CH}_{3}\right)$. MS (LC-MS) m/z. Calculated: 320.30 Found: $359.31[\mathrm{M}+\mathrm{K}]^{+}$.

Synthesis of (E)-3-(2,9,16,23-tetrakis-(4-oxy-3methoxyphenyl)acrylic acid) phthalociyaninato zinc(II) (compound 2): Compound $\mathbf{1}$ was dissolved in $\mathrm{n}$-pentanol ( $3 \mathrm{~mL})$. Anhydrous $\mathrm{Zn}\left(\mathrm{CH}_{3} \mathrm{COO}\right)_{2}(0.156 \mathrm{mmol}, 0.041 \mathrm{~g})$ was added into the solution and the reaction tube was heated to $80{ }^{\circ} \mathrm{C}$ under nitrogen atmosphere. Five drops of DBU were added to the solution and kept at $150-160{ }^{\circ} \mathrm{C}$ for 24 hours. While the temperature was increasing, the color of solution changed from dark brown to dark green. Then, the solution was cooled to room temperature and diluted $\mathrm{HCl}$ was added to arrange of $\mathrm{pH}$ as 2-3. Green precipitates were filtered and washed with water, n-hexane, hot acetone, hot dichloromethane, hot acetonitrile, hot chloroform, hot ethyl acetate, and hot diethyl ether. The dried product was soluble in $\mathrm{MeOH}, \mathrm{EtOH}, \mathrm{THF}, \mathrm{DMSO}$ and DMF. Yield: $0.064 \mathrm{~g} \mathrm{(30 \% ).} \mathrm{M.p.}>300{ }^{\circ} \mathrm{C}$. Anal. Calc. for $\mathrm{C}_{72} \mathrm{H}_{48} \mathrm{ZnN}_{8} \mathrm{O}_{16}$ (MA: $1346.58 \mathrm{~g} / \mathrm{mol}$ ): C, 64.22; H, 3.59; N, 8.32. Found: $C, 64.52 ; H$, $3.45 ; \mathrm{N}, 8.12 \%$. FT-IR $(\mathrm{KBr}), v_{\max } /\left(\mathrm{cm}^{-1}\right): 3300-$ 2500 (broad peak, carboxylic acid-COOH), 3070 $(\mathrm{Ar}-\mathrm{CH}), 2930-2870$ (aliphatic- $\left.\mathrm{CH},-\mathrm{CH}_{3}\right), 1686$ $(\mathrm{C}=\mathrm{O}), 1592-1467(\mathrm{C}=\mathrm{C}), 1259$ (Ar-O-Ar). ${ }^{1} \mathrm{H}-$ NMR (500 MHz, d-DMSO) $\delta$ ppm: 12.30 (s, 4H, $\mathrm{OH})$, 8.05-7.55 (m, 12H, Pc-Ar-H), 7.29-7.16 (m, $12 \mathrm{H}$, subs-Ar-H) 7.45-7.39 (m, 4H, Ar-HC=C), $6.52(\mathrm{~m}, 4 \mathrm{H},-\mathrm{C}=\mathrm{CH}-\mathrm{COO}) 3.35(\mathrm{~s}, 12 \mathrm{H}$ Ar-O$\mathrm{CH}_{3}$ ). UV-vis (DMSO, $\left.1 \times 10^{-5} \mathrm{M}\right): \lambda_{\max } / \mathrm{nm}(\mathrm{log}$ $\varepsilon): 682$ (5.03), 614 (4.36), 349 (4.76). UV-vis (DMF, $\left.1 \times 10^{-5} \mathrm{M}\right): \lambda_{\max } / \mathrm{nm}(\log \varepsilon): 680$ (4.99), 611 (4.30), 352 (4.71). UV-vis (THF, $\left.1 \times 10^{-5} \mathrm{M}\right)$ : $\lambda_{\max } / \mathrm{nm}(\log \varepsilon): 678$ (4.98), 610 (4.30), 348 (4.70). MALDI TOF MS $(\mathrm{m} / \mathrm{z})$ : Calculated: 1346.58, Found: $1346.48 \mathrm{[M}^{+}, 1416.49$ $[\mathrm{M}+2 \mathrm{CI}]^{+}, 1485.84[\mathrm{M}+4 \mathrm{CI}]^{+}$.

\section{RESULT AND DISCUSSION}




\section{Synthesis and Characterization of Compounds}

Scheme 1 shows the general synthesis of the compounds. In the first step of synthesis, trans4-hydroxy-3-methoxycinnamic acid and 4nitrophthalonitrile were dissolved in DMF and anhydrous $\mathrm{K}_{2} \mathrm{CO}_{3}$ was added into the solution. The solution was heated under nitrogen atmosphere for 72 hours at $45-50{ }^{\circ} \mathrm{C}$. Then, the solution was cooled and diluted $\mathrm{HCl}$ was added in the solution to obtain precipitates. The formed precipitate was washed with ultra-pure water for neutralization, the precipitate was then washed with n-hexane and diethyl ether and dried under vacuum. The structure of compound $\mathbf{1}$ was proved by elemental analysis, FT-IR, ${ }^{1} \mathrm{H}-\mathrm{NMR}$, ${ }^{13} \mathrm{C}-\mathrm{NMR}$ and LC-MS techniques.

In the FT-IR spectrum of compound $\mathbf{1}$, there is no peak around $1365 \mathrm{~cm}^{-1}$ corresponding $-\mathrm{NO}_{2}$ groups indicating the full reaction of 4nitrophthalonitrile. Besides, obtained peaks at around $2231 \mathrm{~cm}^{-1}, 1688 \mathrm{~cm}^{-1}$ and a broad peak between $2500-3300 \mathrm{~cm}^{-1}$ on the structure of compound 1 support the $(-\mathrm{C} \equiv \mathrm{N})$, carbonyl $(\mathrm{C}=\mathrm{O})$ and carboxyl groups $(\mathrm{COOH})$, respectively. Indeed, no peaks at around $3380 \mathrm{~cm}^{-1}(-\mathrm{OH})$ supporting the reaction of trans-4-hydroxy-3methoxycinnamic acid to form of compound $\mathbf{1}$. Aliphatic $-\mathrm{CH}$ and $-\mathrm{CH}_{3}$ peaks at around 2981$2844 \mathrm{~cm}^{-1}$ and Ar-O-Ar etheric peak at $1246 \mathrm{~cm}^{-}$ ${ }^{1}$ support the formation of compound $\mathbf{1}$.

${ }^{1} \mathrm{H}-\mathrm{NMR}$ analysis of compound $\mathbf{1}$ also proves the formation of expected structure of this compound. Chemical shifts at around 7.85-7.83, 7.69-7.65 and 7.41-7.39 ppm correspond to aromatic protons to which the nitrile groups are attached. Other aromatic protons were determined in 7.27, 7.21 and 7.19-7.18 ppm as total of three protons. The chemical shifts at around 7.29, 6.53-6.50 and 3.78 ppm were related with $\mathrm{Ar}-\mathrm{CH}=\mathrm{C}$ for one proton bonded aromatic ring, $\mathrm{C}=\mathrm{CH}-\mathrm{COO}$ for one proton and $\mathrm{OCH}_{3}$ for three protons, respectively. The signal at $12.45 \mathrm{ppm}$ was related with $-\mathrm{OH}$ group (22). ${ }^{1} \mathrm{H}-\mathrm{NMR}$ spectrum supports the formation of compound $\mathbf{1}$ with total of 12 protons. ${ }^{13} \mathrm{C}-\mathrm{NMR}$ analysis of compound $\mathbf{1}$ also supports the formation of proposed structure of this compound. The carbon peaks bonded with nitrile groups were determined at 116.65 and 116.39 ppm. The $-\mathrm{OCH}_{3}$ bonded carbon peak was also observed at around of $56.56 \mathrm{ppm} .{ }^{13} \mathrm{C}-\mathrm{NMR}$ spectrum also demonstrates the formation of compound $\mathbf{1}$ with total of 18 peaks for the carbon atom.

The observed peak at $359.31[\mathrm{M}+\mathrm{K}]^{+}$in the mass spectrum also confirms structure of compound $\mathbf{1}$. Finally, the results of experimental elemental analysis data are consistent with the theoretical data of compound $\mathbf{1}$ and are satisfactory for the formation of this compound.
Compound $\mathbf{2}$ was synthesized by cyclotetramerization of compound $\mathbf{1}$ in presence of $\mathrm{Zn}(\mathrm{OAC})_{2}$ and $\mathrm{DBU}$ in dry n-pentanol at 150$160{ }^{\circ} \mathrm{C}$ (Scheme 1). Upon addition of diluted $\mathrm{HCl}$ to solution of the mixture until $\mathrm{pH} 2-3$, carboxylic acid group bearing compound $\mathbf{2}$ were obtained. The obtained product was washed many times different solvents and was dried under vacuum. In the synthesis of tetra-substituted zinc(II) phthalocyanine, a mixture of four possible structural isomers occurs. These isomers can be explained by their molecular symmetry as $\mathrm{C}_{\mathrm{s}}, \mathrm{C}_{2 \mathrm{v}}$, $C_{4 h}$ and $D_{2 h}$. Herein, the synthesized compound 2 is formed as isomer mixtures as expected. No attempt was made for separating the isomers of compound $\mathbf{2}$. The structure of compound $\mathbf{2}$ was verified by FT-IR, elemental analysis, UV-Vis, ${ }^{1} \mathrm{H}-$ NMR, and MALDI-TOF MS techniques. The results are consistent with the expected structure.

In the FT-IR spectrum of compound $\mathbf{2}$, the any peak was observed at around $2231 \mathrm{~cm}^{-1}$ supported formation of compound $\mathbf{2}$ by cyclotetramerization reaction. Besides, the peaks at around $1686 \mathrm{~cm}^{-1}$ and $2500-3300 \mathrm{~cm}^{-1}$ on the structure of compound $\mathbf{2}$ belong to the carboxyl group $(-\mathrm{C}=\mathrm{O})$ and carboxylic acid group, respectively. The peaks at $1259 \mathrm{~cm}^{-1}$ and 2930$2870 \mathrm{~cm}^{-1}$ are related with $\mathrm{Ar}-\mathrm{O}-\mathrm{Ar}$ ether and aliphatic $-\mathrm{CH}$ and $-\mathrm{CH}_{3}$ supporting the formation of compound $\mathbf{2}$.

The ${ }^{1} \mathrm{H}$ NMR spectrum of compound $\mathbf{2}$ exhibits quite broad signals when compared with that of starting compound $\mathbf{1}$ derivative. The $\mathrm{OH}$ protons were observed with a total of 4 protons at 12.30 $\mathrm{ppm}$. The Pc ring protons were detected between 8.05 and $7.55 \mathrm{ppm}$ integrating for a total of 12 protons. Aromatic functional group protons were observed with a total of 12 protons at $7.16 \mathrm{ppm}$. The protons with a total number of 8 at 7.45-7.39 and $6.52 \mathrm{ppm}$ belong to $\mathrm{Ar}-\mathrm{CH}=\mathrm{C}-$ and $-\mathrm{C}=\mathrm{CH}-$ COO- groups, respectively. Finally, the protons with a total number of 12 were observed at around $3.35 \mathrm{ppm}$ as singlet for the $-\mathrm{O}-\mathrm{CH}_{3}$ groups.

UV-Vis spectrophotometry plays an important role to clarify the structure of metallo-Pcs. Pcs are colored substances and give specific absorption peaks in the visible and ultraviolet regions. Pcs show typical UV-Vis spectra with two characteristic absorption bands, one in the UV region at about $300-400 \mathrm{~nm}$ is the $B$ band and the other one in the visible region at $600-700 \mathrm{~nm}$ is the $\mathrm{Q}$ band, both are based on $\pi-\pi^{*}$ transitions (37). The $\mathrm{Q}$ band is also a characteristic peak for differentiating metallo and metal-free Pcs. While the metal-free Pcs give two equal bands at 600$700 \mathrm{~nm}$, the metallo Pcs give a single band. UVVis spectra of compound $\mathbf{2}$ were recorded in THF, DMF, and DMSO solvents and can be seen in Figure 1. These spectra show monomeric behavior evidenced by a single (narrow) $\mathrm{Q}$ band (at around 678-682 nm) in THF, DMF, and DMSO. The $\mathrm{Q}$ band and its shoulder of compound $\mathbf{2}$ were 
determined as a single band at 682 and $614 \mathrm{~nm}$ in DMSO, 680 and 611 in DMF, and 678 and 609 $\mathrm{nm}$ in THF, respectively and $\mathrm{B}$ band of compound 2 was also observed at $349 \mathrm{~nm}$ in DMSO, $352 \mathrm{~nm}$ in DMF, and 348 in THF, respectively supported the formation of compound $\mathbf{2}$. The obtained compound $\mathbf{2}$ exhibits a single $\mathrm{Q}$ band, indicating that it contains the metal ion in the macrocyclic cavity.<smiles>COc1cc(/C=C/C(=O)O)ccc1O</smiles>

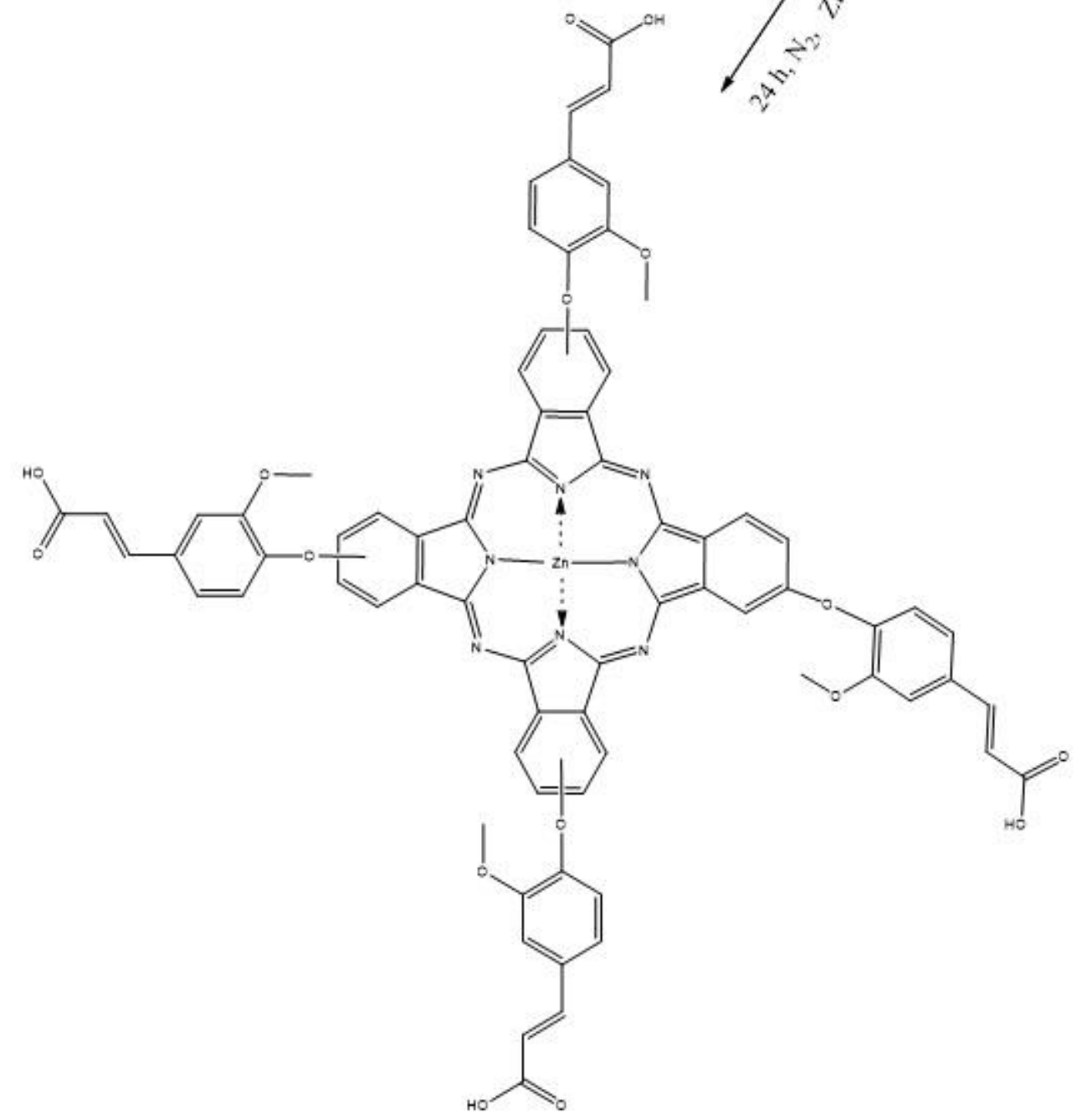

Scheme 1: General synthesis procedure of compounds $\mathbf{1}$ and $\mathbf{2}$. 


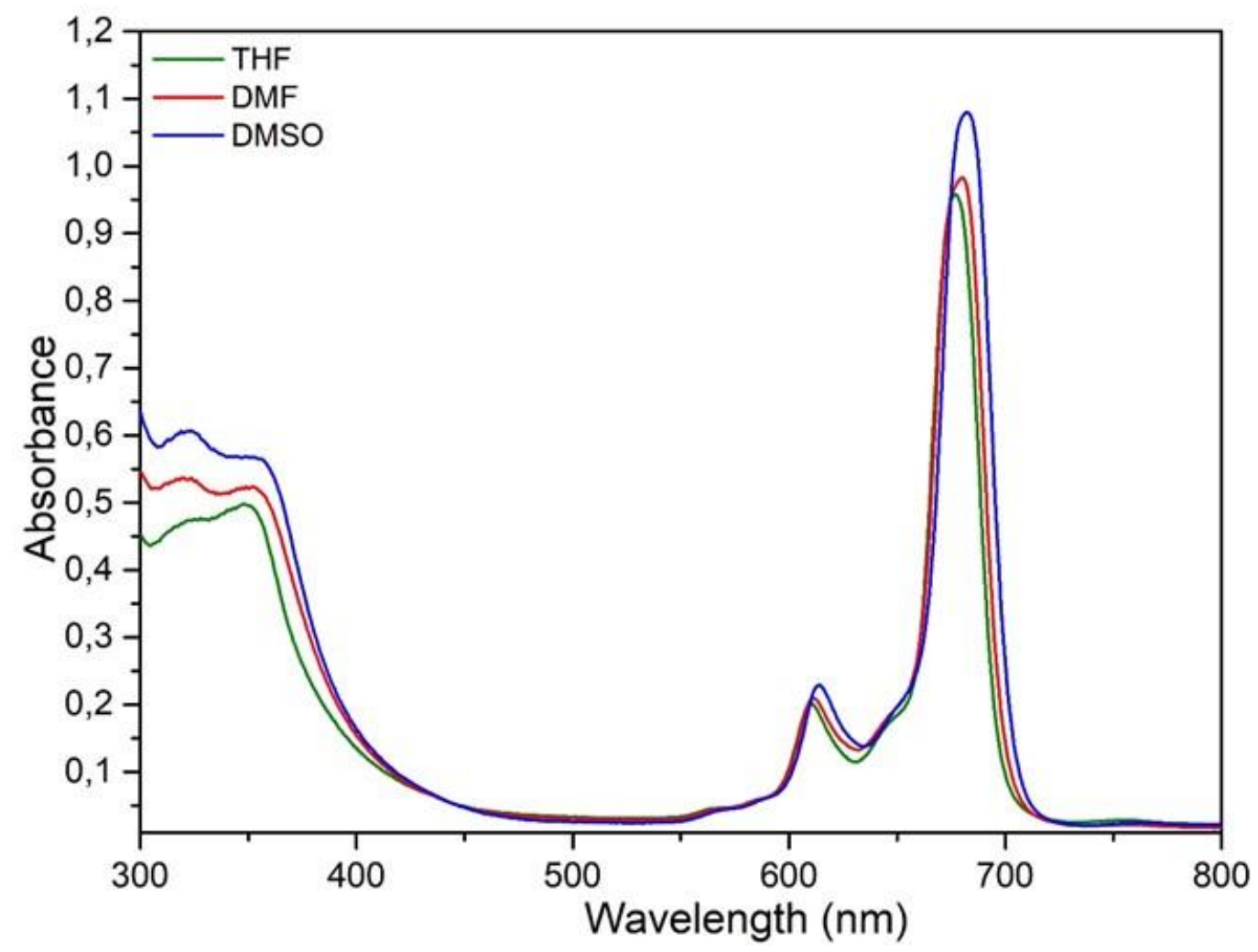

Figure 1: UV-vis spectra of compound $\mathbf{2}$ in different solvents.

The obtained $[\mathrm{M}]^{+} \mathrm{m} / \mathrm{z}: 1346.48,[\mathrm{M}+2 \mathrm{Cl}]^{+}$ $\mathrm{m} / \mathrm{z}: 1416.49,[\mathrm{M}+4 \mathrm{Cl}]^{+} \mathrm{m} / \mathrm{z}: 1485.84$ peaks in MALDI TOF MS spectrum also support the formation of compound $\mathbf{2}$ (Figure 2). Finally, the results of experimental elemental analysis data are consistent with the theoretical data of compound $\mathbf{2}$ and are satisfactory for the formation of this compound.

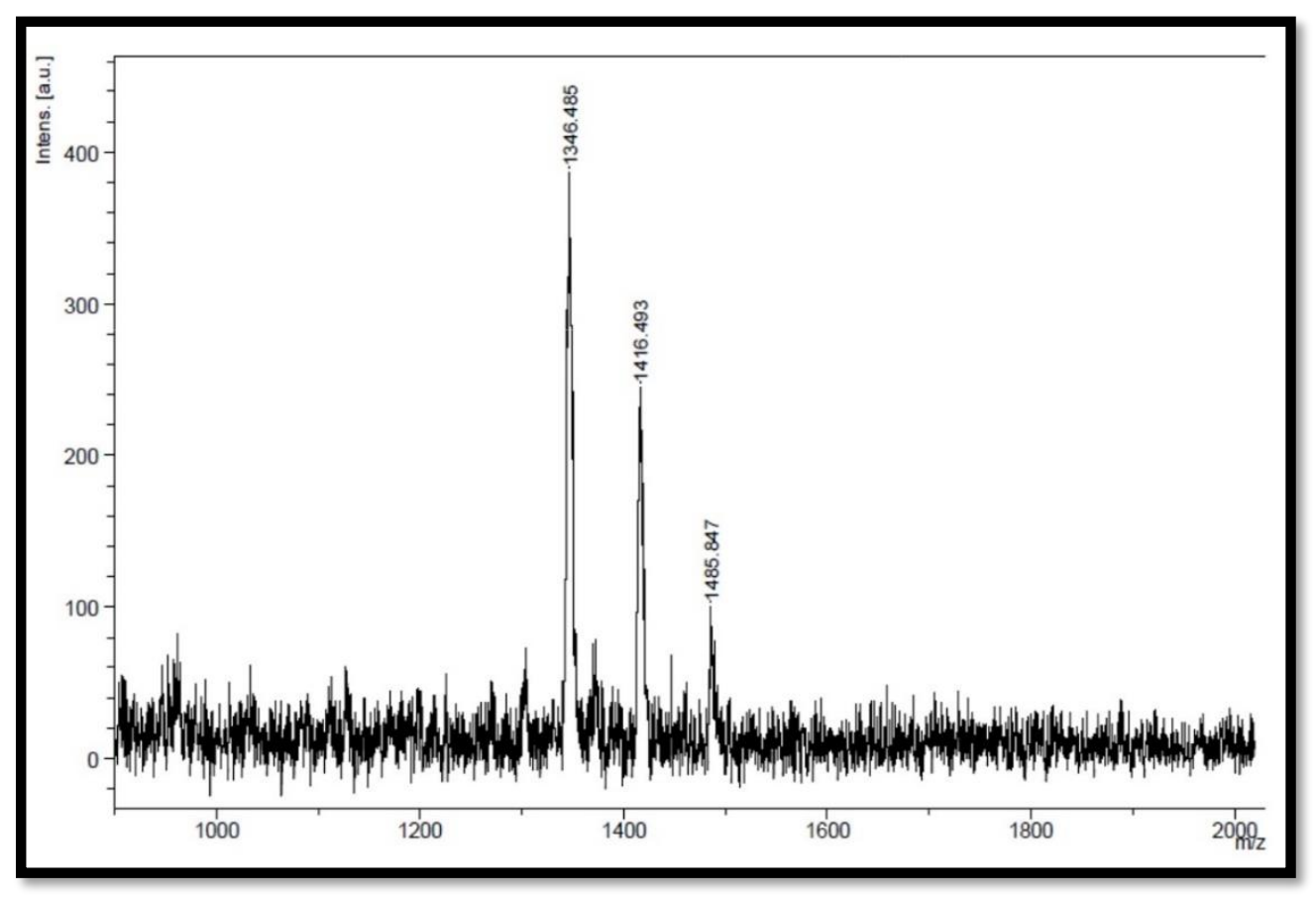

Figure 2: MALDI-TOF MS spectrum of compound 2.

\section{Aggregation properties of compound 2}

The aggregation properties of Pcs have been known since the discovery of these substances $(38,39)$. Generally, aggregation is a common association of molecules in solution, which is the overlaying of two or more macro-ring structures due to intermolecular attraction forces. A coplanar relation of macrocyclic rings and progresses through the assembly of monomers to dimers and higher-order aggregates are effective on aggregation behavior. With aggregation, the structure of compound can change from 
monomer to dimeric, trimeric, or oligomeric structure. The structure of the Pcs (neutral, metal, cationic, etc.), size, position of the substituent group, substituents in the peripheral position, solvent and temperature are very effective on aggregation. In the case of Pcs aggregation, the interactions between the electronic molecules change the physical and chemical properties. Aggregation is the most important factor affecting the photochemical and photophysical behavior of Pcs. The resolution of Pcs is reduced due to aggregation and this is an unwanted situation in applications such as PDT $(40,41)$. In particularly, in water and other polar solvents, the macrocyclic Pc becomes an aggregate due to its hydrophobic nature. For this reason, DMSO and DMF solvents which are dipolar aprotic solvents, have similar physical properties and which do not cause aggregation have been chosen. Water, DMSO and DMF are used in many similar applications. Aggregation not only leads to a decrease in solubility, but also decreases the quantum efficiency of fluorescence and singlet oxygen. This means that the sensitivity to light for $\mathrm{Pc}$ is reduced (42). To reduce these limiting factors and maintain effective photoactivity, Pc may be substituted with various ligands, such as carboxylic acid groups at the peripherally position (24). In this study, the purpose of the aggregation assay is to examine whether compound $\mathbf{2}$ conforms to the Lambert-Beer law in DMSO and DMF solvents at specific concentrations and to determine if they have undergone aggregation. To make these measurements, the solutions of compound $\mathbf{2}$ in DMSO and DMF were separately prepared. The UV-vis spectra for compound $\mathbf{2}$ were examined in both DMSO and DMF under different concentrations ranging from $12 \times 10^{-6} \mathrm{M}$ to $2 \times 10^{-6} \mathrm{M}$. UV-Vis spectra in Figures 3 and 4 show the aggregation behavior of compound $\mathbf{2}$ in DMSO and DMF, respectively. At the end of this investigation, it was found that the compound $\mathbf{2}$ conformed to the Lambert-Beer law and there was no aggregation in DMF and DMSO. When Figures 3 and 4 are examined, it is seen that due to the increase in concentration, the Q-band rises but there are no new bands (normally blueshifted) due to aggregation. The linear variation in the absorbance of the $\mathrm{Q}$ band with increasing concentration confirms that there is no tendency to aggregation.

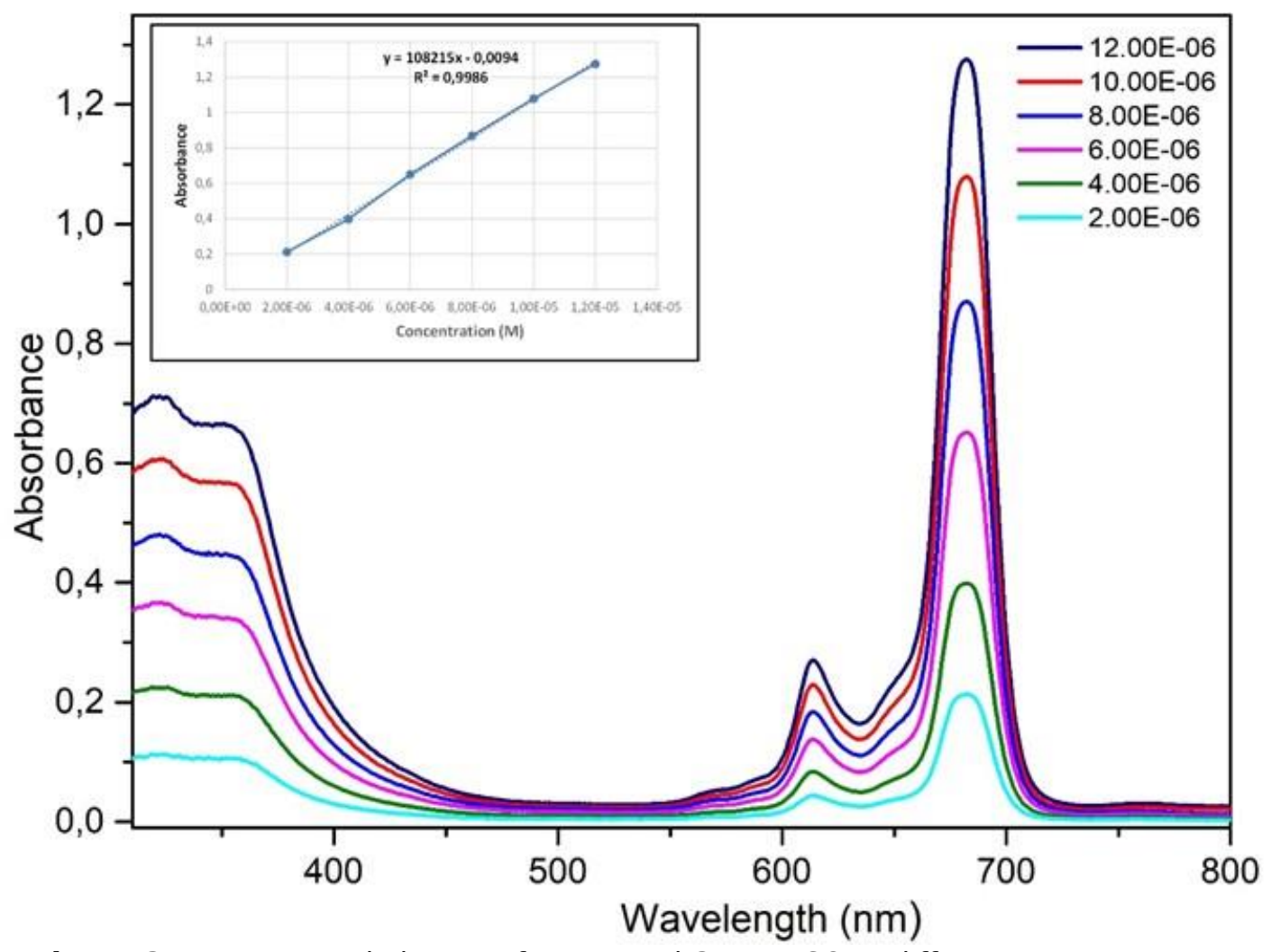

Figure 3: Aggregation behavior of compound $\mathbf{2}$ in DMSO at different concentrations (Inset: Absorbances versus concentrations). 


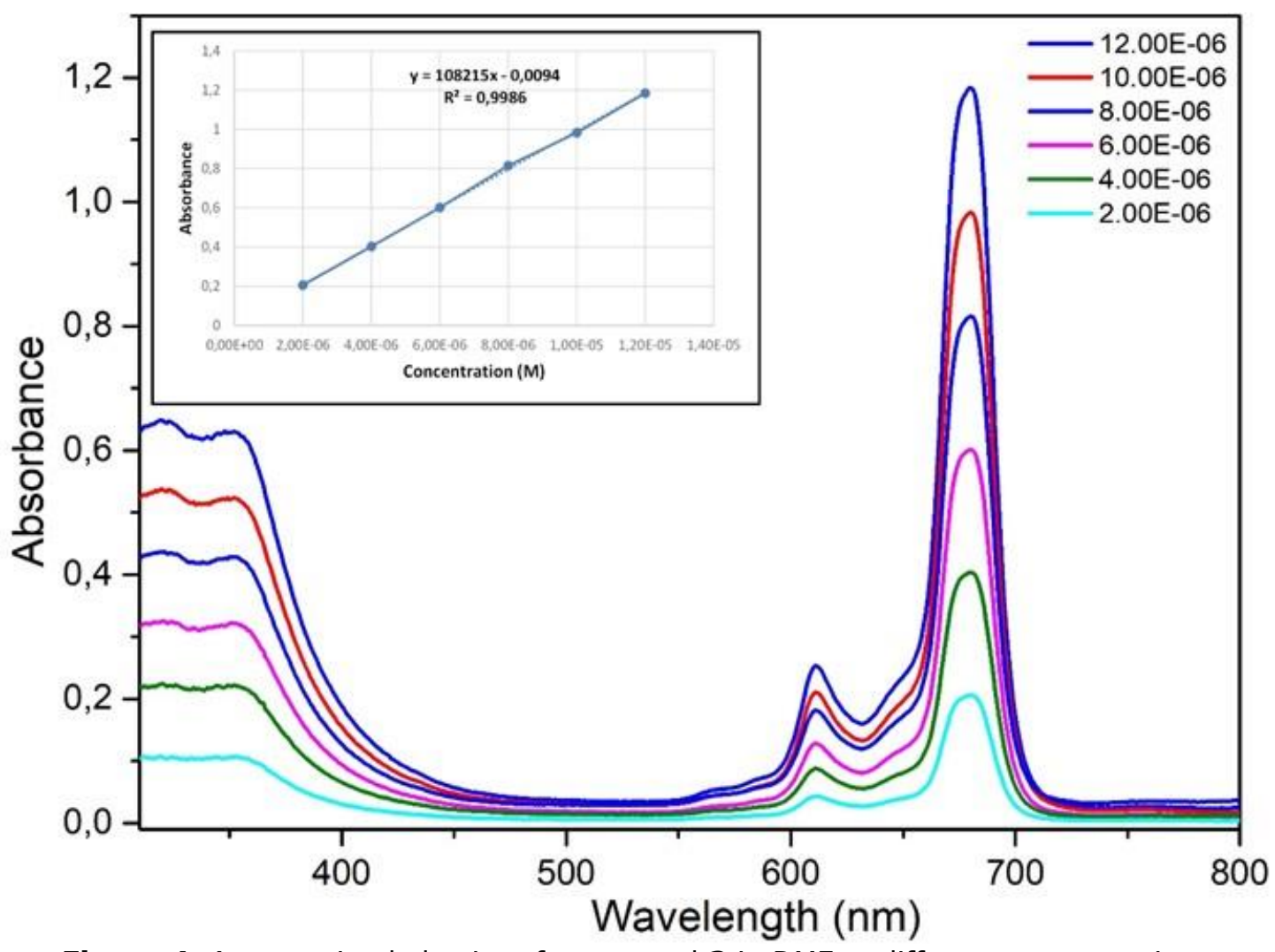

Figure 4: Aggregation behavior of compound $\mathbf{2}$ in DMF at different concentrations (Inset: Absorbances versus concentrations).

\section{Photophysical properties of compound 2}

The fluorescence excitation, emission, and absorption spectra of compound $\mathbf{2}$ in DMSO and DMF are depicted in Figures 5 and 6 , respectively. Table 1 also shows fluorescence emission, excitation, absorption peaks and stokes shift values of compound 2. Stokes shift values have been found in the observed region. The observed stokes shifts for compound $\mathbf{2}$ are 12 in DMSO and are 10 in DMF. The obtained stokes shifts of the compound have been found to be compatible with unsubstituted zinc(II) phthalocyanine (43). The compound exhibits similar fluorescence behavior in both solvents, excitation and absorption spectra are similar and they appear to be mirror images in both solvents. The wavelengths of the $\mathrm{Q}$ band of absorption and the $\mathrm{Q}$ band of excitation is proximity and this situation assumes that the nuclear configurations of the ground and excited states are similar and they are not affected by excitation (44). One of the important problems affecting fluorescent behavior of PCS is aggregation. The reason for this is that the compounds of agglomerated phthalocyanine do not have fluorescence in the solution medium. Compound 2 obtained in this work did not exhibit any aggregation in DMSO and DMF. For this reason, the compound $\mathbf{2}$ exhibits fluorescence behavior in both solvents. 


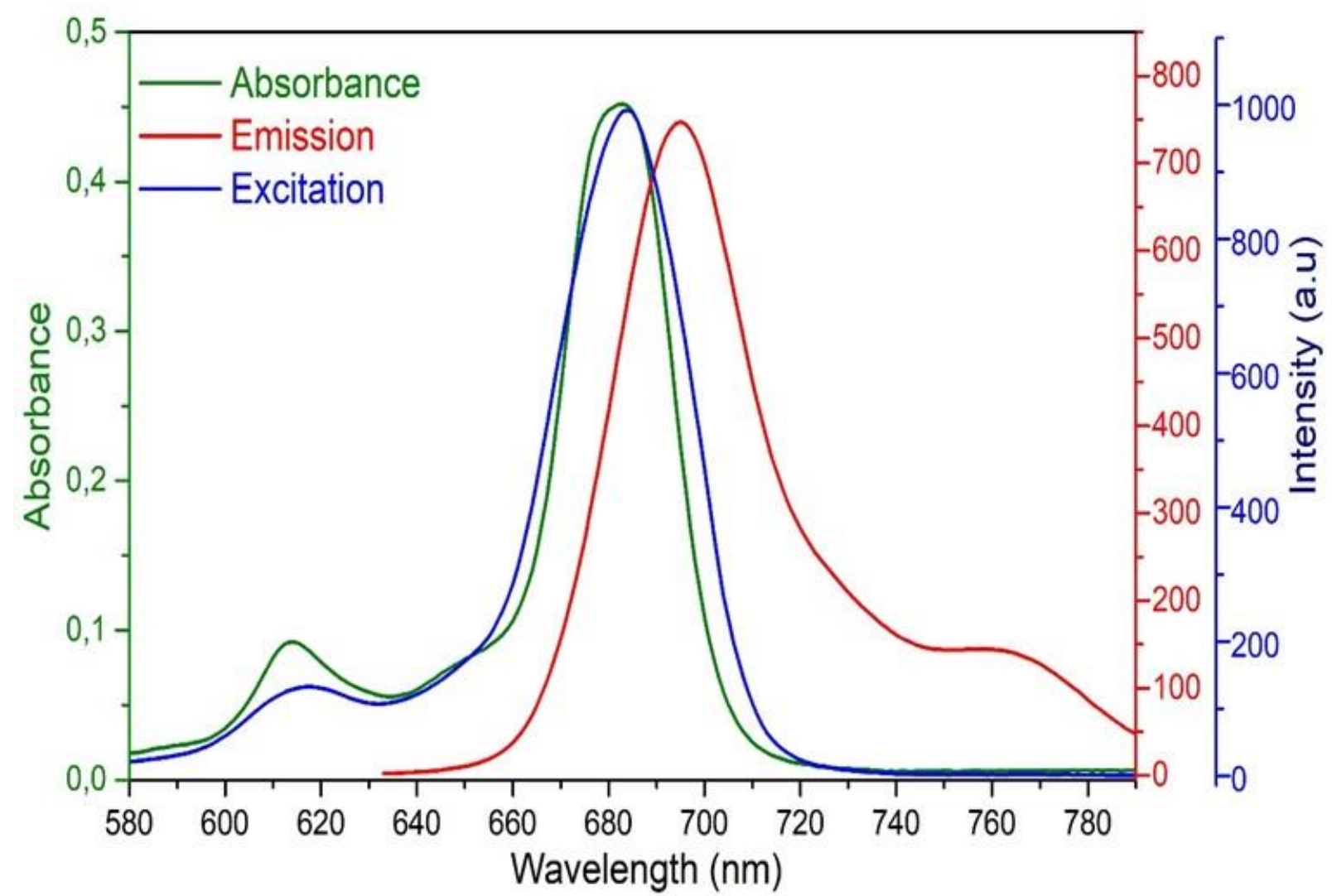

Figure 5: Absorption, emission and excitation spectra for compound $\mathbf{2}$ in DMSO.

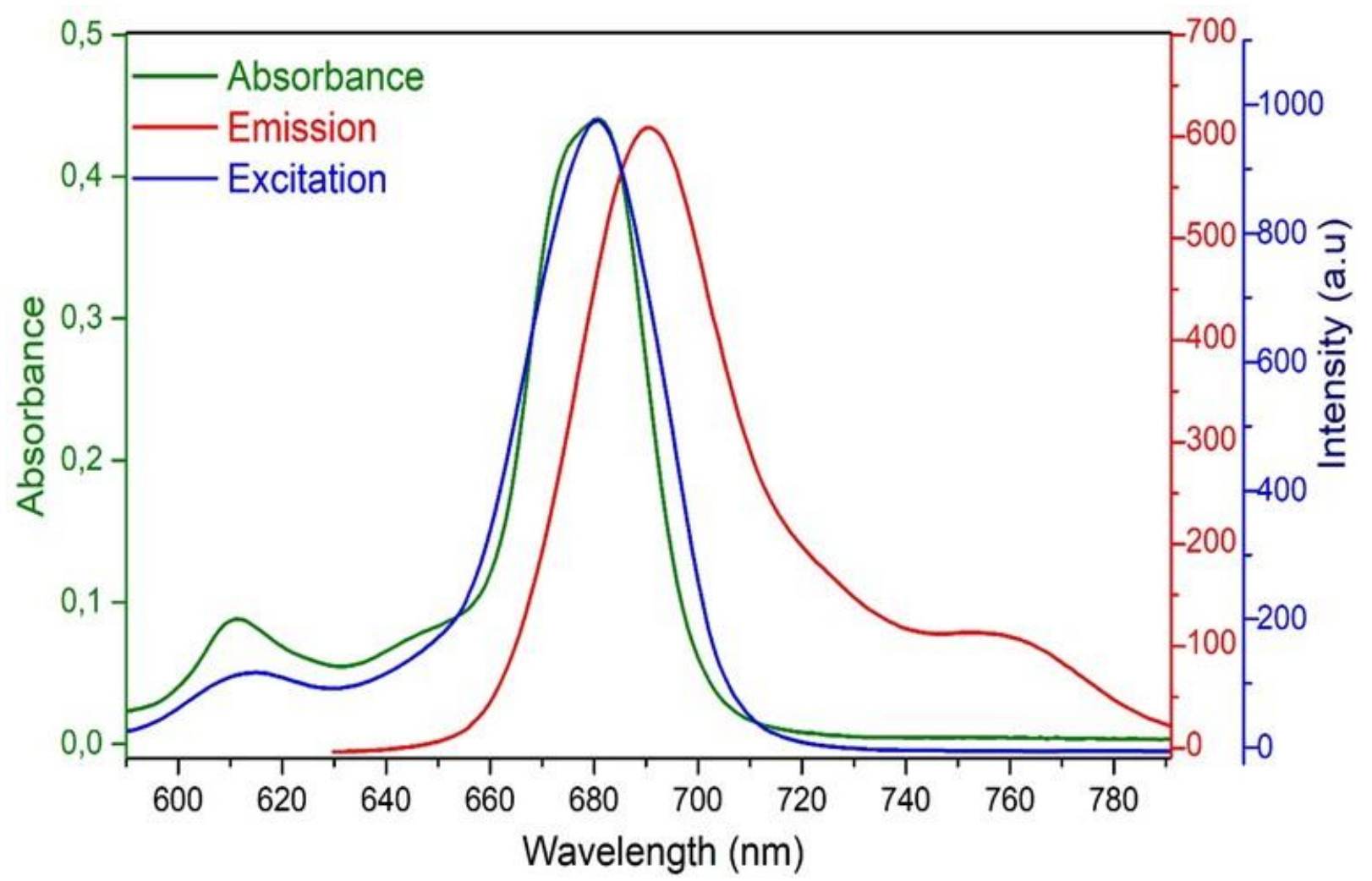

Figure 6: Absorption, emission and excitation spectra for compound 2 in DMF.

Table 1: Absorption, excitation and emission spectral data for compound $\mathbf{2}$ in DMSO and DMF.

\begin{tabular}{ccccccc}
\hline $\begin{array}{c}\text { Compound } \\
\text { name }\end{array}$ & Solvent & $\begin{array}{c}\mathbf{Q} \text { band } \lambda_{\max } \\
\mathbf{( n m )}\end{array}$ & $\mathbf{L o g} \boldsymbol{E}$ & $\begin{array}{c}\text { Excitation } \\
\lambda_{\text {Ex, }} \mathbf{( n m )}\end{array}$ & $\begin{array}{c}\text { Emission } \\
\lambda_{\text {Em, }}(\mathbf{n m})\end{array}$ & $\begin{array}{c}\text { Stokes shift } \\
\boldsymbol{\Delta}_{\text {stokes }(\mathbf{n m})}\end{array}$ \\
\hline $\mathbf{2}$ & DMSO & 682 & 5.03 & 683 & 695 & 12 \\
$\mathbf{2}$ & DMF & 680 & 4.99 & 681 & 691 & 10 \\
\hline
\end{tabular}


The photophysical properties such as fluorescence quantum yield of photosensitizers are highly significant parameters in PDT applications because of the imaging necessity of the photosensitizer in the human body. The fluorescence quantum yields $\left(\Phi_{\mathrm{F}}\right)$ for compound $\mathbf{2}$ in both DMSO and DMF are given in Table 2 . The $\Phi_{\mathrm{F}}$ values for compound $\mathbf{2}$ in both solvents are compatible with typical zinc(II) Pcs (29) and are found similar with $\Phi_{F}$ values of unsubstituted standard zinc(II) phthalocyanine in DMSO and DMF (29). These values reveal that the substitution groups of compound $\mathbf{2}$ are not have important effect on the fluorescence behavior. But the solvent may have little effect (45). Therefore, the compound $\mathbf{2}$ has showed slightly higher $\Phi_{F}$ values in DMSO $(0.23)$ compared to DMF (0.17).

Table 2: Photophysical and photochemical data for compound $\mathbf{2}$ in DMSO and DMF.

\begin{tabular}{cccc}
\hline Solvent & $\boldsymbol{\Phi}_{\mathbf{F}}$ & $\boldsymbol{\Phi}_{\mathbf{d}}\left(\mathbf{1 0}^{-5}\right)$ & $\boldsymbol{\Phi}_{\boldsymbol{\Delta}}$ \\
\hline DMSO & 0.23 & 1.08 & 0.57 \\
DMF & 0.17 & 4.44 & 0.45 \\
\hline
\end{tabular}

\section{Photochemical properties of compound 2}

The photochemical properties include values such as singlet oxygen quantum yields and photodegradation quantum yields. Pcs act as photosensitizers in PDT of some cancers. The photosensitizer, which is activated by a certain light, is excited and molecular oxygen is converted into a reactive oxygen species such as singlet oxygen. This singlet oxygen helps to destroy the cancerous cells. Because singlet oxygen is highly reactive, it can normally damage healthy cells. But it is unstable, it exists very briefly and its effective area is short. Therefore, healthy cells can be minimally damaged (12). The calculation of the singlet oxygen quantum yield is important in PDT. In this study, for singlet oxygen quantum yield measurements; the solutions of compound $\mathbf{2}$ in both DMSO and DMF at $1 \times 10^{-5} \mathrm{M}$ concentration were prepared and then 1,3difenilisobenzofuran (DPBF) (quencher) which prepared at $3 \times 10^{-5}$ concentration was added into these solutions. The mixtures were exposed to light of $2.20 \times 10^{16}$ photon/(s.cm $\left.{ }^{2}\right)$ intensity at a certain time and UV-Vis spectra of these mixture were separately taken. The change in absorption at $417 \mathrm{~nm}$ of the DPBF compound was investigated and singlet oxygen quantum yields were calculated using Eq. 2. The same procedure was made for std-ZnPc in DMSO and DMF for comparative purposes. Figures 7 and 8 show the UV-Vis spectral changes during the measurement of singlet oxygen quantum yield of the compound 2 in DMSO and DMF. The figures show that the concentration of DPBF decreases over time with light irradiation. The $\mathrm{Q}$ band intensity of compound $\mathbf{2}$ does not show a significant change as a result of exposure to light, indicating that the compound is not degraded during single oxygen measurements (Figures 7 and 8). The calculated data are given in Table 2 . The results show that the calculated $\Phi_{\Delta}$ values in DMSO and DMF are slightly lower than the std-ZnPc (29). Substituted groups in the peripheral locations may cause in a slightly lower $\Phi_{\Delta}$ value. It is known in the literature that Pcs containing substituted groups in peripheral positions reduce singlet oxygen generation (46). Although compound $\mathbf{2}$ has slightly low $\Phi_{\Delta}$, it has enough singlet oxygen generation as photosensitizers for PDT application area. The obtained values of singlet oxygen quantum yields for compound $\mathbf{2}$ in DMSO and DMF are typical for metal Pcs $(47,48)$. 


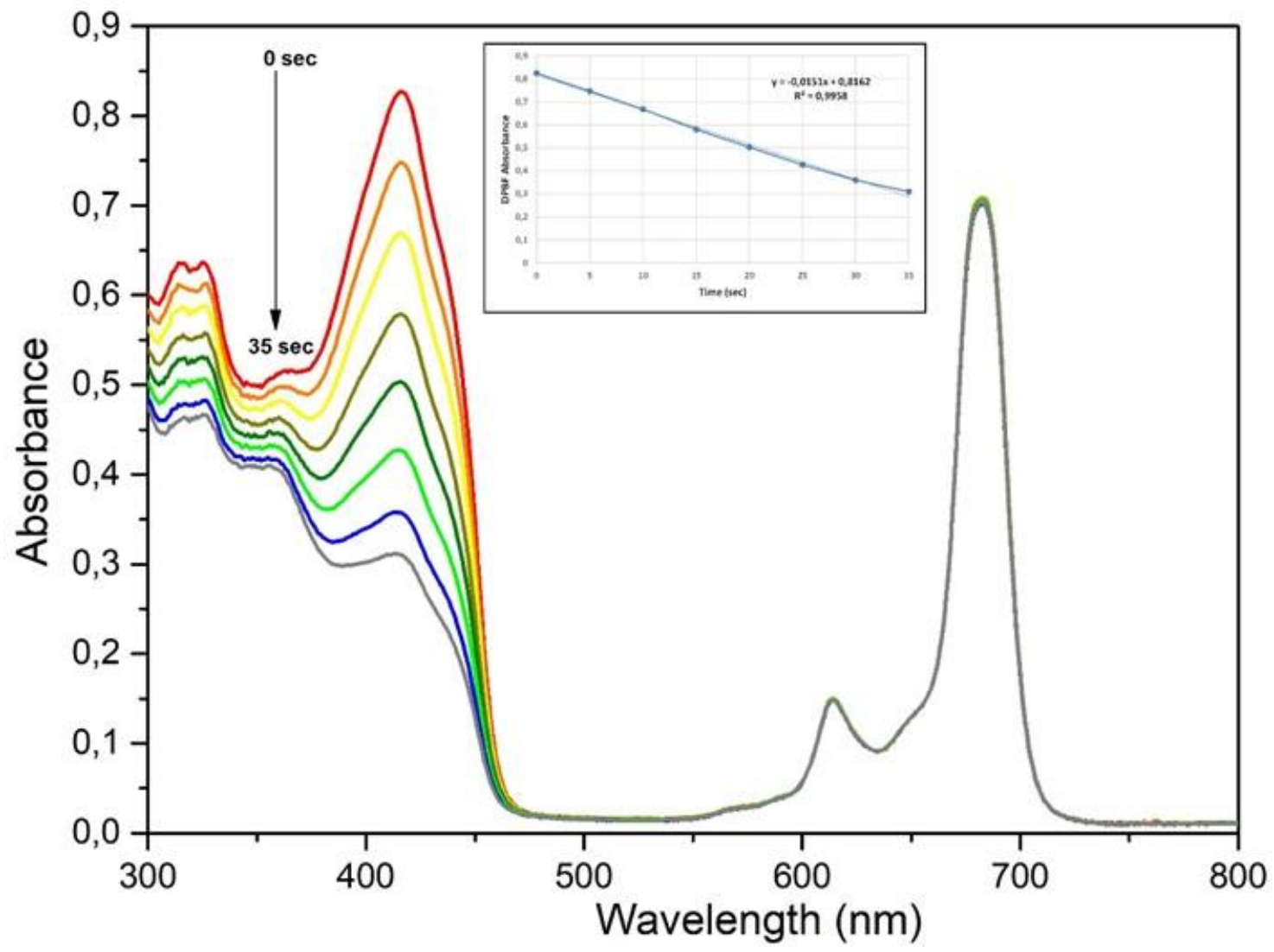

Figure 7: A typical spectrum for the compound $\mathbf{2}$ during the determination of singlet oxygen quantum yield in DMSO (Inset: Plot of DPBF absorbance versus time).

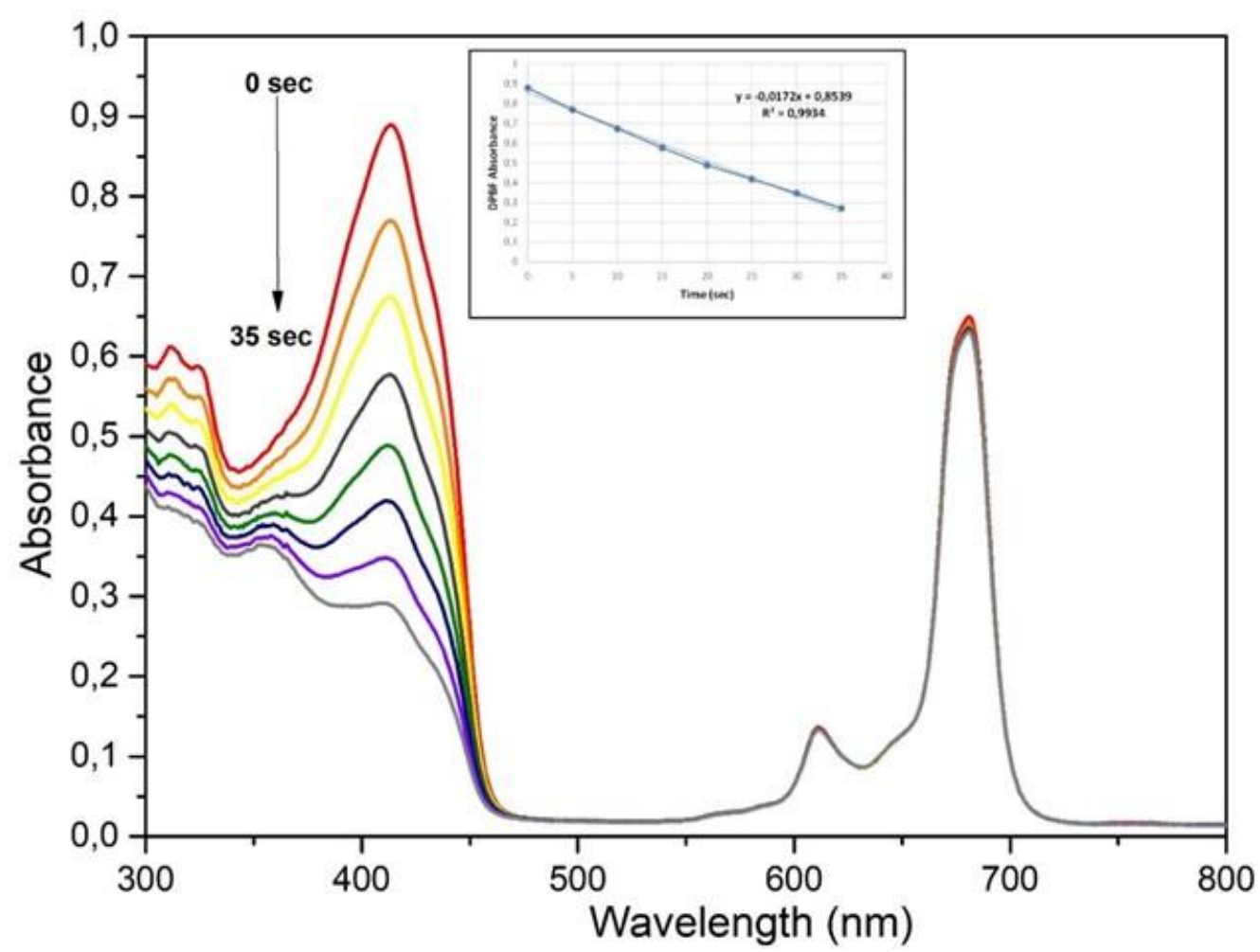

Figure 8: A typical spectrum for the compound $\mathbf{2}$ during the determination of singlet oxygen quantum yield in DMF (Inset: Plot of DPBF absorbance versus time).

When Pcs are exposed to light irradiation during measurement, they may be degraded. This process is an important parameter for the use of Pcs as photosensitizers. Photodegradation quantum yield $\left(\Phi_{\mathrm{d}}\right)$ is durability of a molecule against light. $\Phi_{\mathrm{d}}$ can be calculated by examining the change in the absorption spectrum of compound during the light irradiation. Photodegradation in Pcs is observed with a decrease in the $\mathrm{Q}$ band. The photodegradation 
quantum yields are calculated through Eq. 3 using the slopes of the calibration graphs generated at specific time intervals. In this study, the sensitivity of the compound to light was measured. For these measurements, firstly, the solutions of the compound $\mathbf{2}$ in both DMSO and DMF solvents were separately prepared and then the mixtures were exposed to light of $7.05 \times 10^{15}$ photon. $\mathrm{s}^{-1} \cdot \mathrm{cm}^{-2}$ intensity at a certain time and UV-Vis spectra of these mixtures were separately taken and the change in the $\mathrm{Q}$ band of compound 2 was investigated. Figure 9 for DMSO solution and Figure 10 for DMF solution show absorbance change during photodegradation quantum yield measurements of compound $\mathbf{2}$ showing the decreasing of the $\mathrm{Q}$ and $\mathrm{B}$ bands. As it can be seen from figures, there are no significant decrease in
$\mathrm{Q}$ band of compound $\mathbf{2}$ in both solvents. The $\Phi_{\mathrm{d}}$ values of compound $\mathbf{2}$ in DMSO and DMF were found the order of $10^{-5}$ (Table 2). Ordinary values for stable Pcs are of the order of $10^{-6}$, but these values for unstable PCs are of the order of $10^{-3}$ (49). The $\Phi_{d}$ value of compound 2 is $1.08 \times 10^{-5}$ in DMSO and is $4.44 \times 10^{-5}$ in DMF. These values are typical for zinc Pcs bearing different substituents on the peripherally as described in the literature $(50,52)$. The $\Phi_{d}$ value in DMSO is slightly lower than unsubstituted zinc(II) phthalocyanine $\left(\Phi_{\mathrm{d}}: 2.61 \times 10^{-5}\right)$. But the $\Phi_{\mathrm{d}}$ value in DMF is slightly higher than unsubstituted zinc(II) phthalocyanine $\left(\Phi_{\mathrm{d}}: 2.30 \times 10^{-5}\right)$. According to the data obtained, compound $\mathbf{2}$ in DMSO is slightly stable than compound $\mathbf{2}$ in DMF due to having lower $\Phi_{\mathrm{d}}$ value.

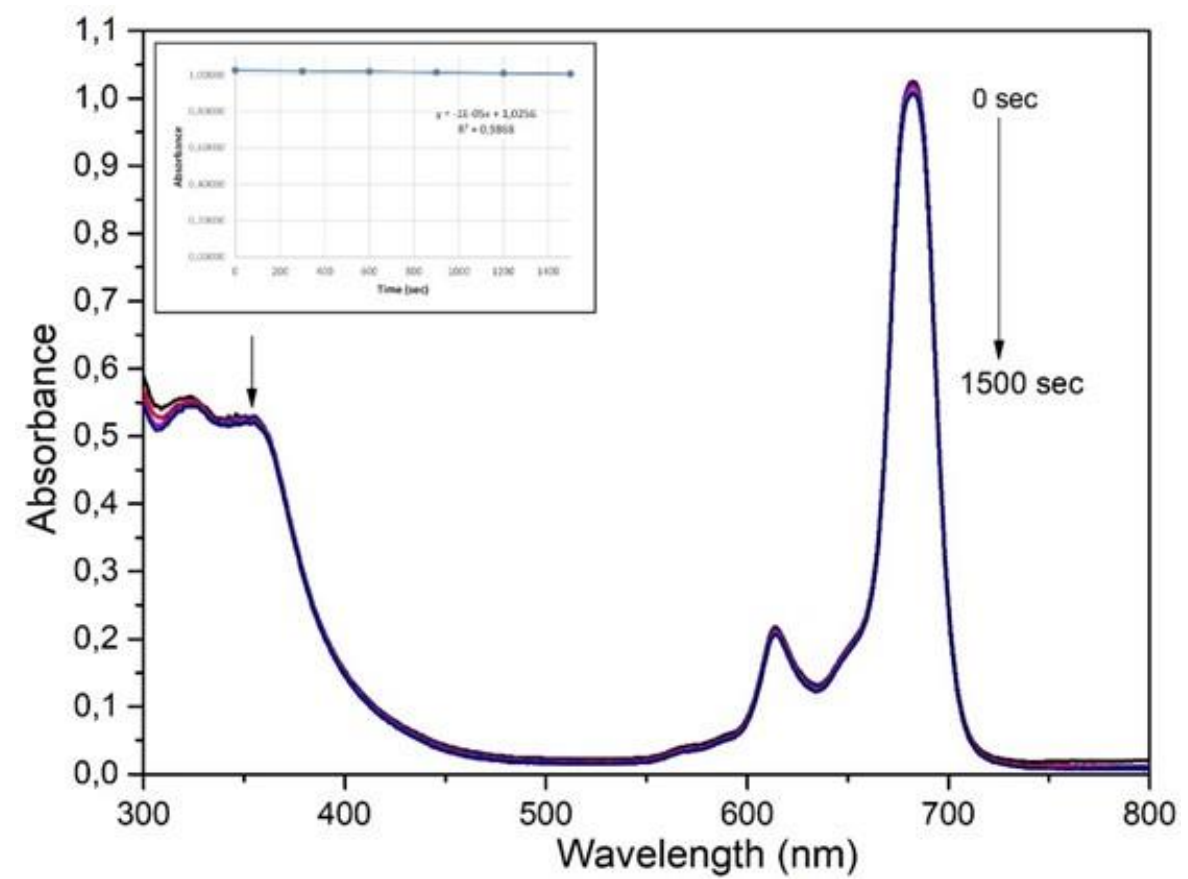

Figure 9: Absorbance changes during the photodegradation study of compound $\mathbf{2}$ in DMSO (Inset: plot of $\mathrm{Q}$ band absorbance versus time). 


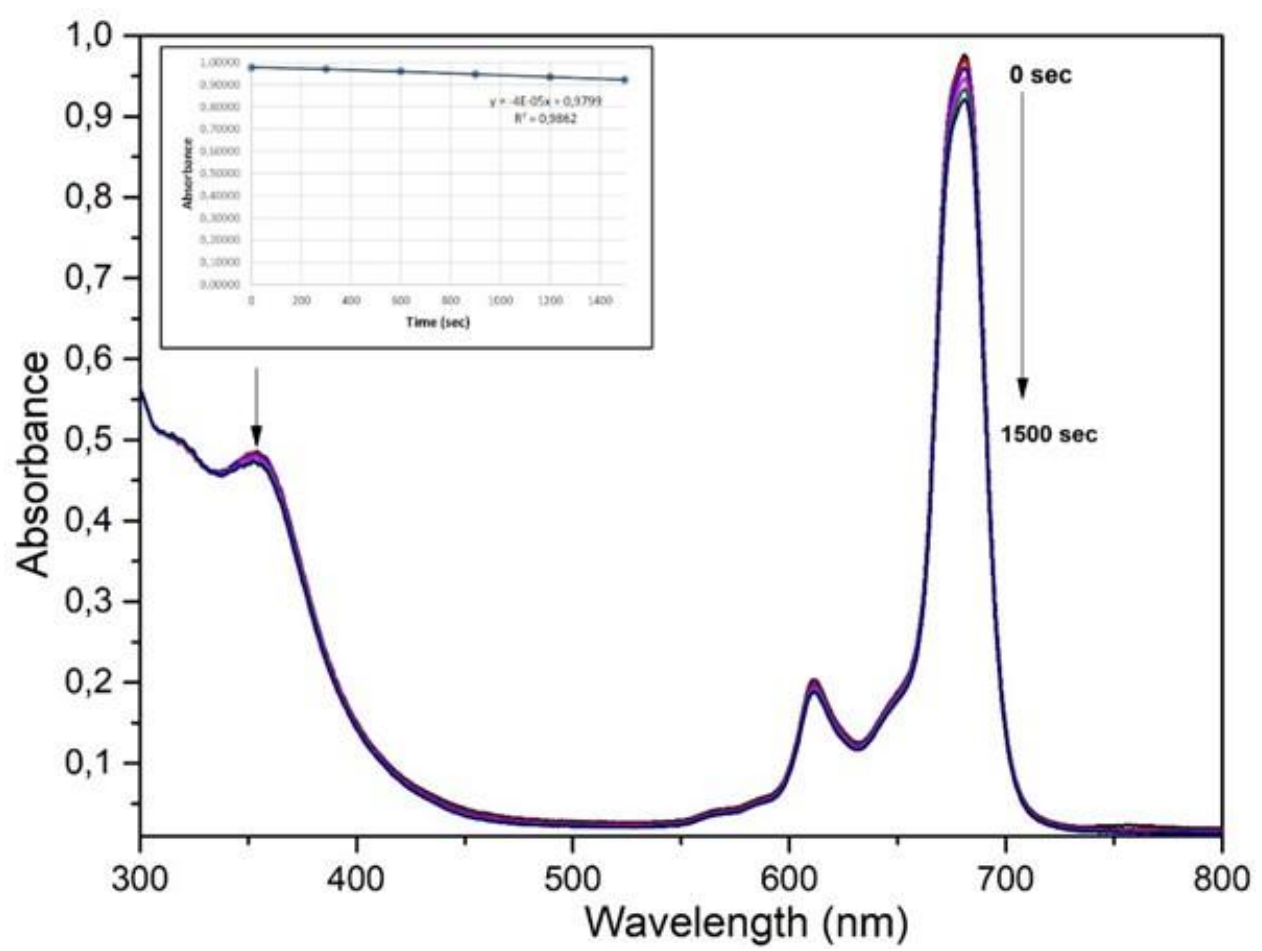

Figure 10: Absorbance changes during the photodegradation study of compound 2 in DMF (Inset: plot of $\mathrm{Q}$ band absorbance versus time).

\section{CONCLUSION}

In summary, this study reports synthesis, characterization and photochemical and photophysical properties of ferulic acid substituted zinc(II) phthalocyanine for the first time. The synthesized phthalocyanine has solubility in many solvents such as THF, DMSO and DMF and it does not exhibit any aggregation in the mentioned solvents. Fluorescence quantum yield, singlet oxygen quantum yield and photodegradation quantum yield of this phthalocyanine were also determined in DMSO and DMF solvent to reveal their potential in PDT applications. This phthalocyanine gives good results as photosensitizers for PDT treatment.

\section{ACKNOWLEDGEMENTS}

Thanks to Prof. Dr. Ayşe Gül Gürek and Mohamad Albakour from Gebze Technical University for their contributions.

Conflict of interest: The authors declare that they have no conflict of interest.

\section{REFERENCES}

1. Leznoff CC, Lever ABP, Stuzhin P, Khelevina O, Berezin B. Phthalocyanines: properties and applications: VCH publishers; 1996.

2. Gorduk S, Avciata O, Avciata U. Photocatalytic degradation of methylene blue under visible light irradiation by non-peripherally tetra substituted phthalocyanine- $\mathrm{TiO}_{2}$ nanocomposites. Inorg Chim Acta. 2018;471:137-47.
3. Gottfried JM. Surface chemistry of porphyrins and phthalocyanines. Surf Sci Rep. 2015;70(3):259-379.

4. Aktaş A, Acar I, Bıyıklıoğlu Z, Saka ET, Kantekin H. Synthesis, electrochemistry of metalfree, copper, titanium phthalocyanines and investigation of catalytic activity of cobalt, iron phthalocyanines on benzyl alcohol oxidation bearing 4-\{2-[3-trifluoromethyl) phenoxy] ethoxy\} groups. Synth Met. 2014;198:212-20.

5. Durmuş M, Lebrun C, Ahsen V. Synthesis and characterization of novel liquid and liquid crystalline phthalocyanines. J Porphyrins Phthalocyanines. 2004;8(10):1175-86.

6. Guillaud G, Simon J, Germain J. Metallophthalocyanines: Gas sensors, resistors and field effect transistors1. Coord Chem Rev. 1998; 178:1433-84.

7. Bouvet $M$. Radical phthalocyanines and intrinsic semiconduction. The Porphyrin Handbook: Elsevier; 2003. p. 37-103.

8. Walter MG, Rudine AB, Wamser CC. Porphyrins and phthalocyanines in solar photovoltaic cells. J Porphyrins Phthalocyanines. 2010;14(09):75992.

9. Koyun Ö, Gördük S, Keskin B, Çetinkaya A, Koca A, Avcrata U. Microwave-assisted synthesis, electrochemistry and spectroelectrochemistry of phthalocyanines bearing tetra terminal-alkynyl functionalities and click approach. Polyhedron. 2016;113:35-49. 
10. Karaca H, Kurt Z, Sezer S. Synthesis of Novel Chalcone Substituted Metallophthalocyanines: Electrochemistry, Spectroelectrochemistry, and Catalytic Oxidation of 2-mercaptoethanol. JOTCSA.5(2):701-18.

11. Oluwole DO, Sarı FA, Prinsloo E, Dube E, Yuzer $A$, Nyokong $T$, İnce $M$. Photophysicochemical properties and photodynamic therapy activity of highly watersoluble Zn(II) phthalocyanines. Spectrochimica Acta, Part A : Molecular and Biomolecular Spectroscopy. 2018;203:236-243.

12.Bonnett R. Photosensitizers of the porphyrin and phthalocyanine series for photodynamic therapy. Chem Soc Rev. 1995;24(1):19-33.

13. Dolmans DE, Fukumura D, Jain RK. Photodynamic therapy for cancer. Nature reviews cancer. 2003;3(5):380.

14. Nas A, Dilber G, Durmuş $M$, Kantekin $H$. The influence of the various central metals on photophysical and photochemical properties of benzothiazole-substituted phthalocyanines. Spectrochimica Acta Part A: Molecular and Biomolecular Spectroscopy. 2015;135:55-62.

15. Macdonald IJ, Dougherty TJ. Basic principles of photodynamic therapy. J Porphyrins Phthalocyanines. 2001;5(02):105-29.

16. Günsel A. Comparative Studies of Photophysicochemical Properties of NonPeripherally Anisole/Thioanisole-Tetrasubstituted Gallium (III) Phthalocyanines Containing Oxygen/Sulfur Bridge. JOTCSA. 2017;5(1):26982.

17. Dumoulin F, Durmuş $M$, Ahsen V, Nyokong T. Synthetic pathways to water-soluble phthalocyanines and close analogs. Coord Chem Rev. 2010;254(23-24):2792-847.

18. Makhseed S, Machacek M, Alfadly W, Tuhl A, Vinodh $M$, Simunek T, et al. Water-soluble nonaggregating zinc phthalocyanine and in vitro studies for photodynamic therapy. Chem Commun. 2013;49(95):11149-51.

19. Kliesch H, Weitemeyer A, Müller S, Wöhrle D. Synthesis of phthalocyanines with one sulfonic acid, carboxylic acid, or amino group. Liebigs Annalen. 1995;1995(7):1269-73.

20. Opris DM, Nuesch F, Löwe C, Molberg M, Nagel $M$. Synthesis, characterization, and dielectric properties of phthalocyanines with ester and carboxylic acid functionalities. Chem Mater. 2008;20(21):6889-96.

21. Sevim AM, Arıkan S, Koca A, Gül A. Synthesis and spectroelectrochemistry of new phthalocyanines with ester functionalities. Dyes and Pigments. 2012;92(3):1114-21.
22. Tekdaş DA, Gürek AG, Ahsen V. Asymmetric zinc phthalocyanines substituted with a single carboxyl and triethyleneoxysulfonyl groups: synthesis, characterization and validation for photodynamic therapy. J Porphyrins Phthalocyanines. 2014;18(10-11):899-908.

23. Verdree VT, Pakhomov S, Su G, Allen MW, Countryman AC, Hammer RP, et al. Water soluble metallo-phthalocyanines: the role of the functional groups on the spectral and photophysical properties. J Fluoresc. 2007;17(5):547-63.

24. Liu W, Jensen TJ, Fronczek FR, Hammer RP, Smith KM, Vicente MGH. Synthesis and cellular studies of nonaggregated water-soluble phthalocyanines. J Med Chem. 2005;48(4):103341.

25. Ke M-R, Huang J-D, Weng S-M. Comparison between non-peripherally and peripherally tetrasubstituted zinc(II) phthalocyanines as photosensitizers: Synthesis, spectroscopic, photochemical and photobiological properties. ] Photochem Photobiol A. 2009;201(1):23-31.

26. Özgül G, Taştemel A, Özkaya AR, Bulut M. Synthesis, characterization and comparative electrochemistry of beta and alpha tetra-[4-oxy3-methoxybenzoic acid]-substituted $\mathrm{Zn}$ (II), $\mathrm{Co}(\mathrm{II})$ and $\mathrm{Cu}(\mathrm{II})$ phthalocyanines. Polyhedron. 2015;85:181-89.

27. Fery-Forgues S, Lavabre D. Are fluorescence quantum yields so tricky to measure? A demonstration using familiar stationery products. J Chem Educ. 1999;76(9):1260.

28. Maree MD, Nyokong T, Suhling K, Phillips D. Effects of axial ligands on the photophysical properties of silicon octaphenoxyphthalocyanine. J Porphyrins Phthalocyanines. 2002;6(06):37376.

29. Ogunsipe A, Chen J-Y, Nyokong T. Photophysical and photochemical studies of zinc(II) phthalocyanine derivatives-effects of substituents and solvents. New J Chem. $2004 ; 28(7): 822-27$.

30. Gürol I, Durmuş $M$, Ahsen V, Nyokong $T$. Synthesis, photophysical and photochemical properties of substituted zinc phthalocyanines. Dalton Transactions. 2007(34):3782-91.

31. Ogunsipe A, Nyokong T. Effects of substituents and solvents on the photochemical properties of zinc phthalocyanine complexes and their protonated derivatives. J Mol Struct. 2004;689(1-2):89-97.

32. Perrin DD, Armarego W, Perrin DR. Purification of Laboratory Chemicals, by DD 
Perrin. WLF Armarego and Dawn R. Perrin: Pergamon Press; 1966.

33. Spiller W, Kliesch H, Wöhrle D, Hackbarth S, Röder B, Schnurpfeil G. Singlet oxygen quantum yields of different photosensitizers in polar solvents and micellar solutions. J Porphyrins Phthalocyanines. 1998;2(2):145-58.

34. Brannon JH, Magde D. Picosecond laser photophysics. Group 3A phthalocyanines. JACS. $1980 ; 102(1): 62-65$.

35. Ogunsipe A, Nyokong T. Photophysical and photochemical studies of sulphonated nontransition metal phthalocyanines in aqueous and non-aqueous media. J Photochem Photobiol A. 2005;173(2):211-20.

36. Seotsanyana-Mokhosi I, Kuznetsova N, Nyokong T. Photochemical studies of tetra-2, 3pyridinoporphyrazines. J Photochem Photobiol A. $2001 ; 140(3): 215-22$.

37. Gorduk S, Koyun O, Avciata O, Altindal A, Avciata U. Synthesis of Peripherally Tetrasubstituted Phthalocyanines and Their Applications in Schottky Barrier Diodes. Journal of Chemistry. 2017;2017.

38. Kadish KM, Smith KM, Guilard LR. The Porphyrin Handbook: Phthalocyanines: Properties and Materials. 2003. Academic Press.

39. Jeong J, Kumar RS, Mergu N, Son Y-A. Photophysical, electrochemical, thermal and aggregation properties of new metal phthalocyanines. J Mol Struct. 2017;1147:46979.

40. Engelkamp $\mathrm{H}$, Nolte RJ. Molecular materials based on crown ether functionalized phthalocyanines. J Porphyrins Phthalocyanines. 2000;4(05):454-59.

41. Dominguez D, Snow A, Shirk J, Pong R. Polyethyleneoxide-capped phthalocyanines: limiting phthalocyanine aggregation to dimer formation. J Porphyrins Phthalocyanines. $2001 ; 5(07): 582-92$.

42. Sibrian-Vazquez M, Ortiz J, Nesterova IV, Fernández-Lázaro F, Sastre-Santos A, Soper SA, et al. Synthesis and properties of cell-targeted $\mathrm{Zn}$ (II)-phthalocyanine-peptide conjugates. Bioconjugate Chem. 2007;18(2):410-20.
43. Ogunsipe $A$, Durmuş $M$, Atilla D, Gürek AG, Ahsen $V$, Nyokong $T$. Synthesis, photophysical and photochemical studies on long chain zinc phthalocyanine derivatives. Synth Met. 2008;158(21-24):839-47.

44. Durmuş $M$, Nyokong $T$. The synthesis, fluorescence behaviour and singlet oxygen studies of new water-soluble cationic gallium (III) phthalocyanines. Inorg Chem Commun. 2007;10(3):332-38.

45. Forster T, Hoffmann G. Viscosity dependence of fluorescent quantum yields of some dye systems. Zeitschrift Fur Physikalische ChemieFrankfurt. 1971;75(1-2):63-\&.

46. Çakır V, Çakır D, Pişkin $M$, Durmuş $M$, Bıyıklığlu Z. New peripherally and nonperipherally tetra-substituted water soluble zinc phthalocyanines: synthesis, photophysics and photochemistry. J Organomet Chem. 2015;783:120-29.

47. Durmuş M, Nyokong T. Synthesis and solvent effects on the electronic absorption and fluorescence spectral properties of substituted zinc phthalocyanines. Polyhedron. 2007;26(12):2767-76.

48. Ogunsipe A, Maree D, Nyokong T. Solvent effects on the photochemical and fluorescence properties of zinc phthalocyanine derivatives. J Mol Struct. 2003;650(1-3):131-40.

49. Maree SE, Nyokong T. Syntheses and photochemical properties of octasubstituted phthalocyaninato zinc complexes. J Porphyrins Phthalocyanines. 2001;5(11):782-92.

50. Nyokong T, Antunes E. Photochemical and photophysical properties of metallophthalocyanines. Handbook of Porphyrin Science (Volume 7) With Applications to Chemistry, Physics, Materials Science, Engineering, Biology and Medicine: World Scientific; 2010. p. 247-357.

51. Durmuş M. Photochemical and photophysical characterization. Photosensitizers in medicine, environment, and security: Springer; 2011. p. 135-266.

52. Albakour M, Tunç G, Akyol B, Kostakoğlu S T, Berber S, Bekaroğlu Ö, Gürek A G. Synthesis, characterization, photophysicochemical properties and theoretical study of novel zinc phthalocyanine containing four tetrathia macrocycles. J Porphyrins Phthalocyanines. 2018; 22(01n03): 77-87. 
